\title{
Protective effects of hydrogen sulfide against angiotensin II-induced endoplasmic reticulum stress in HUVECs
}

\author{
HENG-JING HU ${ }^{1}$, ZHI-SHENG JIANG ${ }^{2}$, JIE QIU ${ }^{1}$, SHENG-HUA ZHOU ${ }^{1}$ and QI-MING LIU ${ }^{1}$ \\ ${ }^{1}$ Department of Cardiology/Cardiac Catheterisation Lab, Second Xiangya Hospital, Central South University, \\ Changsha, Hunan 410011; ${ }^{2}$ Institute of Cardiovascular Disease and Key Lab For Arteriosclerology of Hunan, \\ University of South China, Hengyang, Hunan 421001, P.R. China
}

Received September 25, 2015; Accepted October 5, 2016

DOI: $10.3892 / \mathrm{mmr} .2017 .6238$

\begin{abstract}
The inhibitory effects of hydrogen sulfide $\left(\mathrm{H}_{2} \mathrm{~S}\right)$ on angiotensin II (AngII)-stimulated human umbilical vein endothelial cell (HUVEC) dysfunction remain to be elucidated. Endoplasmic reticulum (ER) stress has been detected in endothelial dysfunction (ED). The present study aimed to determine whether $\mathrm{H}_{2} \mathrm{~S}$ may exert an inhibitory effect on AngII-induced ER stress. Using HUVECs as a model system, the present study used western blotting to detect protein expression, intracellular reactive oxygen species (ROS) levels were determined by oxidative conversion of cell permeable DCFH-DA to fluorescent dichlorofluorescein, CCK-8 assay was used to investigate the cell viability, methylene blue was used to investigate the CSE activity, TUNEL was used to investigate the cells apoptosis. The present study demonstrated that AngII not only upregulated the expression levels of inducible nitric oxide synthase (iNOS), stimulated ROS production and increased cell apoptosis, but also downregulated the expression levels of phosphorylated-endothelial nitric oxide synthase, decreased the expression and activity of cystathionine-c-lyase (CSE) and decreased cell viability. Furthermore, hydrogen peroxide $\left(\mathrm{H}_{2} \mathrm{O}_{2}\right.$; an exogenous ROS) downregulated the expression and activity of CSE, and had similar effects as AngII, whereas the inhibitory effects of AngII were completely suppressed by $\mathrm{N}$-acetyl-L-cysteine (a ROS scavenger). In addition, AngII induced the expression of glucose-regulated protein 78 (GRPP78) and C/EBP homologous protein (CHOP), which are markers of ER stress. Conversely, the stimulatory effects of AngII were completely inhibited by sodium hydrosulfide (NaHS; a $\mathrm{H}_{2} \mathrm{~S}$ donor). Treatment with NaHS attenuated ROS production, inhibited
\end{abstract}

Correspondence to: Professor Qi-Ming Liu, Department of Cardiology/Cardiac Catheterisation Lab, Second Xiangya Hospital, Central South University, 139 W Middle Renmin Road, Changsha, Hunan 410011, P.R. China

E-mail: qimingliuxiangya@hotmail.com

Key words: hydrogen sulfide, angiotensin II, endoplasmic reticulum stress, endothelial dysfunction
CHOP and GRP78 expression, and decreased cell apoptosis. The present study indicated that AngII induced ED via the activation of ER stress in HUVECs. In addition, the effects of AngII on ER stress could be suppressed by $\mathrm{H}_{2} \mathrm{~S}$.

\section{Introduction}

The pathogenesis of cardiovascular disease (CVD) and cardiovascular complications, such as atherosclerosis, is associated with endothelial dysfunction (ED) $(1,2)$. It is well established that ED contributes to the high rates of cardiovascular mortality (3). Excessive oxidative stress, particularly reactive oxygen species (ROS), exerts a diverse atherogenic effect that induces vascular and tissue injuries (4), which are considered to serve an important role in the development of ED.

The renin-angiotensin system (RAS) has long been known to have an important role in the maintenance of cardiovascular function, and electrolyte and fluid balance. Emerging evidence has suggested that angiotensin II (AngII) is a marker of the RAS system, and higher AngII levels correlate with a higher incidence of CVD (5). Furthermore, AngII has been shown to directly regulate vascular resistance and induce cardiac fibrosis-associated gene expression in a mouse model of cardiac dysfunction (6). It has also been hypothesized that overproduction of AngII participates in the progression of CVD via ROS (7). Furthermore, in model rats with hypertensive disease, AngII levels were much higher in endothelial cells compared with in plasma (8). Beyond vasoconstriction, previous studies have demonstrated that AngII exerts cytotoxic effects via the induction of apoptotic endothelial cell death, these effects were associated with phosphorylated-endothelial nitric oxide synthase (p-eNOS) and inducible nitric oxide synthase (iNOS) in a concentration-dependent manner (9-12). Notably, p-eNOS and iNOS have been indicated as biomarkers and novel therapeutic targets in oxidative stress-associated ED (12-15).

The endoplasmic reticulum (ER) is a subcellular organelle in which protein translation, folding and trafficking occur. In addition, inflammation generated by ER stress is cytotoxic to several cell types, and may facilitate the progression of ED. Previous studies have demonstrated that increased ER stress levels are a marker for cardiovascular risk, and are associated with higher levels of oxidative stress and hypoxia $(16,17)$. In addition, numerous studies have reported that several 
conditions, such as diabetes mellitus and cardiovascular disorders, are correlated with increased ER stress levels $(18,19)$. Glucose-regulated protein 78 (GRP78) and C/EBP-homologous protein (CHOP) are biological markers for ER stress $(20,21)$. Furthermore, ER stress is associated with decreased p-eNOS expression $(14,22)$.

A previous study demonstrated that AngII induces ED via ER stress (23). In addition, increased levels of GRP78 and CHOP have been reported to correlate with vascular ED, and decrease the activity of antioxidant enzymes, such as eNOS, in AngII-treated mice, thus suggesting that AngII-induced ED is associated with ER stress $(23,24)$. Hydrogen sulfide $\left(\mathrm{H}_{2} \mathrm{~S}\right)$ can attenuate ER stress by increasing superoxide dismutase expression and reducing ROS levels (25). Furthermore, $\mathrm{H}_{2} \mathrm{~S}$ may attenuate RAS activation via reduced ROS overproduction (26). The present study hypothesized that $\mathrm{H}_{2} \mathrm{~S}$ exerts cytoprotective effects against AngII-induced ED in human umbilical vein endothelial cells (HUVECs) via the inhibition of ER stress.

It has previously been demonstrated that $\mathrm{H}_{2} \mathrm{~S}$ exerts cytoprotective effects against oxidative stress-induced endothelial cell injury via antioxidant defense mechanisms (27). However, to the best of our knowledge, no previous studies have verified whether $\mathrm{H}_{2} \mathrm{~S}$ has any effect on AngII-induced ER stress and ED in HUVECs.

In the present study, HUVECs were treated with AngII to establish a cellular model of ED, and the effects of AngII on ER stress, which is considered a main cause of ED development, were detected. Furthermore, the protective effects of $\mathrm{H}_{2} \mathrm{~S}$ on AngII-induced ER stress were investigated. The effects of $\mathrm{H}_{2} \mathrm{~S}$ on AngII-induced apoptosis and ROS accumulation were also determined, which are important processes in the development of ED.

\section{Materials and methods}

Materials. Dulbecco's modified Eagle's medium (DMEM) and fetal bovine serum (FBS) were obtained from Gibco (Thermo Fisher Scientific, Inc., Waltham, MA, USA). Sodium hydrosulfide (NaHS), AngII, N-acetyl-L-cysteine (NAC), Hoechst 33258, deoxynucleotidyl transferase-mediated dUTP-biotin nick end labeling (TUNEL) and 2',7-dichlorodihydrofluorescein diacetate (DCFH-DA) were purchased from Sigma-Aldrich (Merck Millipore, Darmstadt, Germany). Antibodies targeting iNOS (cat. no. ab15323), p-eNOS (cat. no. ab183046), GRP78 (cat. no. ab21685) and CHOP (cat. no. ab11419), p-eNOS (cat. no. ab183046), GAPDH (cat. no. ab8245) and caspase-12 (cat. no. ab62484) were provided by Abcam (Cambridge, UK). Cystathionine-c-lyase (CSE) antibody was purchased from by Proteintech Group Inc. (Rosemont, IL, USA; cat. no. 12032-1-AP). Cell Counting kit-8 (CCK-8) was obtained from Dojindo China Co., Ltd. (Shanghai, China). Horseradish peroxidase-conjugated IgG $(\mathrm{H}+\mathrm{L})$ secondary antibodies were purchased from Beyotime Institute of Biotechnology (Shanghai, China; cat. nos. A0192 and A0208). All other reagents, unless specified, were purchased from Beyotime Institute of Biotechnology.

Cell culture. HUVECs (Cell Bank of the Type Culture Collection of the Chinese Acadmy of Sciences, Shanghai,
China) were cultured in DMEM supplemented with $10 \%$ FBS at $37^{\circ} \mathrm{C}$ in a humidified atmosphere containing $5 \% \mathrm{CO}_{2}$. Prior to each experiment, the medium was replaced with fresh serum-containing medium unless otherwise indicated. Cells were divided into the following treatment groups: i) Untreated; ii) AngII, consisting of $1 \times 10^{6}$ HUVEC cells treated with $10^{-6} \mathrm{M}$ AngII for 0-24 h; iii) NaHS + AngII, consisting of $1 \times 10^{6}$ HUVEC cells exposed to $200 \mu \mathrm{M}$ NaHS for $60 \mathrm{~min}$ prior to treatment with $10^{-6} \mathrm{M}$ AngII for $24 \mathrm{~h}$; iv) $\mathrm{NAC}+\mathrm{AngII}$, consisting of $1 \times 10^{6}$ HUVEC cells exposed to $100 \mu \mathrm{M}$ NAC for $60 \mathrm{~min}$ prior to treatment with $10^{-6} \mathrm{M}$ AngII for $24 \mathrm{~h}$; v) NaHS, consisting of $1 \times 10^{6}$ HUVEC cells exposed to $200 \mu \mathrm{M}$ NaHS for $24 \mathrm{~h}$; and vi) NAC, consisting of $1 \times 10^{6}$ HUVEC cells exposed to $100 \mu \mathrm{M}$ NAC for $24 \mathrm{~h}$.

Cell viability assay. After the HUVECs were cultured in 96-well plates and had received various treatments, $100 \mu 1$ CCK- 8 was added to each well at a 1/10 dilution, and the eight plates were incubated for a further $2 \mathrm{~h}$ at $37^{\circ} \mathrm{C}$. Absorbance was then measured at $450 \mathrm{~nm}$ using a microplate reader. The mean optical density (OD) of four wells in the indicated groups was used to calculate the percentage of cell viability, according to the following formula: Cell viability $(\%)=$ OD treatment group / OD control group x $100 \%$.

Detection of intracellular ROS generation. After the HUVECs were cultured in 96-well plates and had received various treatments, $10 \mu \mathrm{mol} / 1 \mathrm{DCFH}-\mathrm{DA}$ in serum-free DMEM was added to each well and incubated for a further $30 \mathrm{~min}$ at $37^{\circ} \mathrm{C}$. The cells were then washed three times with serum-free DMEM prior to the detection of dichlorofluorescein fluorescence. A fluorescent microscope connected to an imaging system was used to observe the entire field of vision. Mean fluorescence intensity (MFI) from three random fields was analyzed using ImageJ 1.410 software (National Institutes of Health, Bethesda, MD, USA); MFI was used to represent the amount of ROS.

Measurement of CSE activity. After receiving the various treatments, HUVECs were collected and homogenized in $50 \mathrm{mM}$ ice-cold potassium phosphate buffer ( $\mathrm{pH}$ 6.8). The reaction mixture contained $100 \mathrm{mmol} / \mathrm{l}$ potassium phosphate buffer (pH 7.4), $10 \mathrm{mmol} / \mathrm{l}$ L-cysteine, $2 \mathrm{mmol} / \mathrm{l}$ pyridoxal 5 '-phosphate and $10 \%(\mathrm{w} / \mathrm{v})$ homogenate. Cryovial test tubes $(2 \mathrm{ml})$ were used as the center wells, into which $0.5 \mathrm{ml}$ $1 \%$ zinc acetate was added as the trapping solution and $2 \times 2.5 \mathrm{~cm}$ filter paper was used to increase air:liquid contact surface. The reactions were performed in Erlenmeyer flasks. The flasks containing the reaction mixture and the center wells were flushed with $\mathrm{N}_{2}$, before being sealed with a double layer of parafilm. The reactions were initiated by transferring the flasks from ice to a $37^{\circ} \mathrm{C}$ shaking water bath. Following a $90 \mathrm{~min}$ incubation at $37^{\circ} \mathrm{C}, 0.5 \mathrm{ml}$ of $50 \%$ trichloroacetic acid was added to terminate the reaction. The flasks were then resealed and incubated at $37^{\circ} \mathrm{C}$ for a further $60 \mathrm{~min}$ to ensure the complete trapping of $\mathrm{H}_{2} \mathrm{~S}$ released from the mixture. The contents of the center wells were transferred to test tubes, each containing $3.5 \mathrm{ml}$ water. Subsequently, $0.5 \mathrm{ml} 20 \mathrm{mM}$ $N, N$-dimethyl-p-phenylenediamine sulphate in $7.2 \mathrm{M} \mathrm{HCl}$ was added, immediately followed by the addition of $0.5 \mathrm{ml}$ 
A

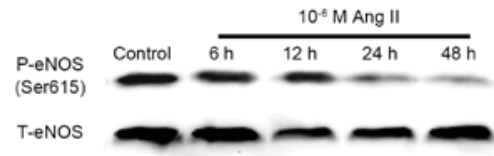

B

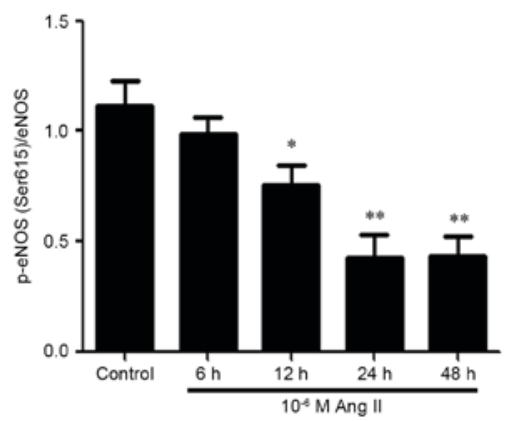

C

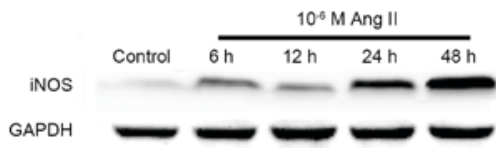

D

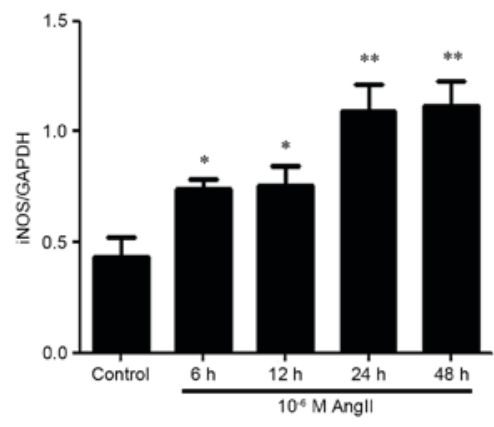

$\mathbf{E}$

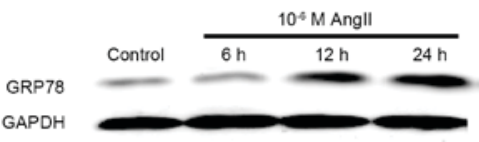

$\mathbf{F}$

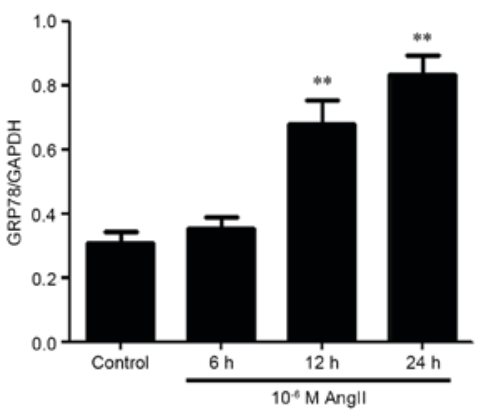

G

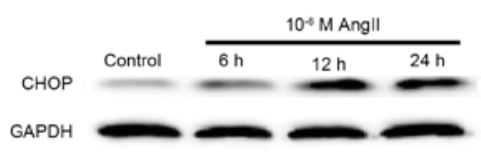

$\mathbf{H}$

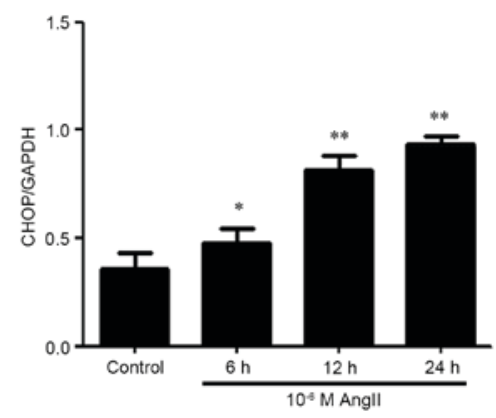

I

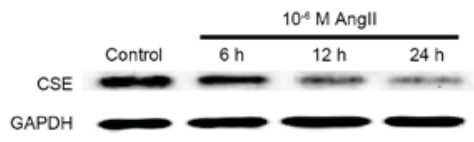

$\mathbf{J}$

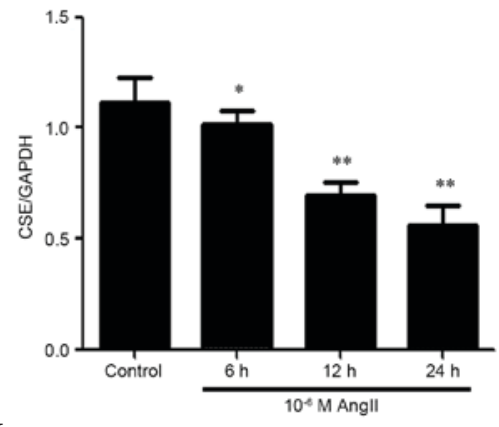

$\mathbf{K}$

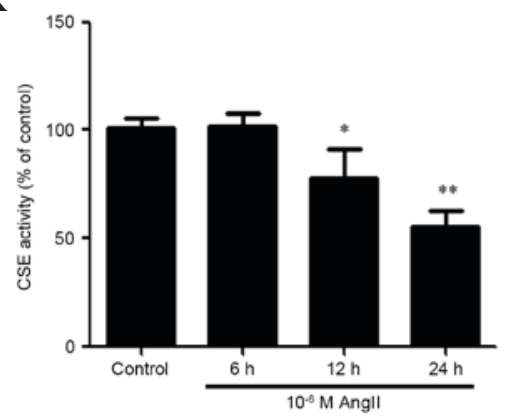

Figure 1. AngII induced cytotoxicity and endoplasmic reticulum stress by inhibiting the expression and activity of cystathionine-c-lyase in human umbilical vein endothelial cells. Cells were treated with $10^{-6} \mathrm{M}$ AngII for the indicated times. The protein expression levels of (A and B) p-eNOS (ser615) and (C and D) iNOS, (E and F) GRP78, (G and H) CHOP and (I and J) CSE were determined by western blotting. were detected by western blotting. (B, D, F, H and J) Blots from A, C, E, G and I were semi-quantified by densitometric analysis. (K) Activity levels of CSE were determined by methylene blue spectrophotometric assay. Data are presented as the mean \pm standard error of the mean $(n=3)$. ${ }^{* *} \mathrm{P}<0.01,{ }^{*} \mathrm{P}<0.05$ vs. the control group. AngII, angiotensin II; p-eNOS, phosphorylated-endothelial nitric oxide synthase; T total; iNOS, inducible nitric oxide synthase; GRP78, glucose-regulated protein 78; CHOP, C/EBP-homologous protein; CSE, cystathionine-c-lyase.

$30 \mathrm{mM} \mathrm{FeCl}{ }_{3}$ in $1.2 \mathrm{M} \mathrm{HCl}$. After $20 \mathrm{~min}$, the absorbance of the resultant solution was measured at $670 \mathrm{~nm}$ using a spectrophotometer.

Western blot analysis. After the indicated treatments, the cells were washed three times with PBS and were collected according to the cell suspension method. The cells were then lysed in lysis buffer on ice for $30 \mathrm{~min}$. The resulting cell lysates were clarified by centrifugation at $10,943 \times \mathrm{x}$ for $15 \mathrm{~min}$ at $4^{\circ} \mathrm{C}$. Proteins were quantified using the bicinchoninic acid method.

Total proteins $(300 \mathrm{ng})$ were separated by $10 \%$ SDS-PAGE and were electroblotted onto polyvinylidene fluoride membranes. The membranes were blocked with $5 \%(\mathrm{w} / \mathrm{v})$ non-fat dry milk containing $0.1 \%(\mathrm{v} / \mathrm{v})$ Tween 20 for $1 \mathrm{~h}$, and were then incubated with GRP78 (1:800), CHOP $(1: 2,000)$, p-eNOS (Ser615; 1:1,000), iNOS $(1: 1,000)$, CSE $(1: 1,000)$ and caspase-12 (1:2,000) antibodies overnight at $4^{\circ} \mathrm{C}$. Subsequently, secondary antibodies $(1: 1,000)$ were incubated for $1 \mathrm{~h}$ at room temperature. Membranes were visualized using an enhanced chemiluminescence 
kit according to the manufacturer's protocols (Beyotime Institute of Biotechnology) and relative protein expression levels were semi-quantitively analyzed by densitometry using QuantityOne software (version 4.62; Bio-Rad Laboratories, Inc., Hercules, CA, USA).

Determination of HUVEC apoptosis. The apoptosis of HUVECs was detected using TUNEL and Hoechst 33258 staining. TUNEL staining was performed using an In Situ Cell Death Detection kit, according to the manufacturer's protocol. Briefly, after the indicated treatments, cells were fixed with 4\% paraformaldehyde in PBS for $10 \mathrm{~min}$. After three washes in PBS, the cells were stained with $50 \mu 1$ TUNEL dye for $1 \mathrm{~h}$, after which the cells were rinsed briefly with PBS and were air-dried. Subsequently, the cells were visualized under a florescence microscope. Apoptotic cells with condensed nuclei exhibited green fluorescence, whereas viable cells displayed normal nuclear size and uniform florescence.

Hoechst 33258 staining was also conducted. Briefly, after the indicated treatments, cells were fixed with $4 \%$ paraformaldehyde in PBS for 10 min. After three washes in PBS, cells were stained with $5 \mathrm{mg} / \mathrm{l}$ Hoechst 33258 dye for $10 \mathrm{~min}$ before being rinsed briefly with PBS and air-dried. The cells were then visualized under a florescence microscope. Apoptotic cells with condensed nuclei exhibited blue fluorescence, whereas viable cells displayed normal nuclear size and uniform florescence. The ratios of different fluorescent densities from 4 random fields was analyzed using ImageJ (version 1.41o; imagej.nih.gov/ij/). The experiment was repeated 3 times.

Statistical analysis. Data are presented as the mean \pm standard error of the mean. Differences between groups were analyzed by one-way analysis of variance followed by Bonferroni's correction. Data were analyzed using SPSS 15.0 (SPSS, Inc., Chicago, IL, USA). P $<0.05$ was considered to indicate a statistically significant difference.

\section{Results}

AngII induces cytotoxicity and ER stress by inhibiting the expression and activity of CSE in HUVECs. iNOS and phosphorylation of eNOS (ser615) (an essential step in eNOS activation) have been reported to be involved in AngII cytotoxicity $(28,29)$ and ED (30). Therefore, the present study investigated whether AngII could induce ED through alterations in the expression levels of p-eNOS (ser615) and iNOS in HUVECs. As presented in Fig. 1, untreated HUVECs failed to produce detectable levels of iNOS, whereas AngII-treated cells produced high levels of iNOS. Conversely, the other ED marker, p-eNOS (ser615), was reduced in AngII-treated cells. ER stress has been reported to be associated with AngII in mice (31,32); therefore, the present study further observed the effects of AngII on the expression of ER stress-associated molecules, such as GRP78 and CHOP. Similar to iNOS, AngII was able to induce GRP78 and CHOP expression. Conversely, CSE expression and activity was reduced in a time-dependent manner following AngII treatment.

Stimulation of ROS production inhibits the expression and activity of CSE in AngII-treated HUVECs. Oxidative stress, which is generated by AngII, can induce endothelial cell
A

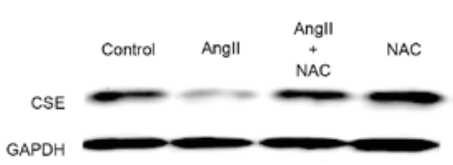

B

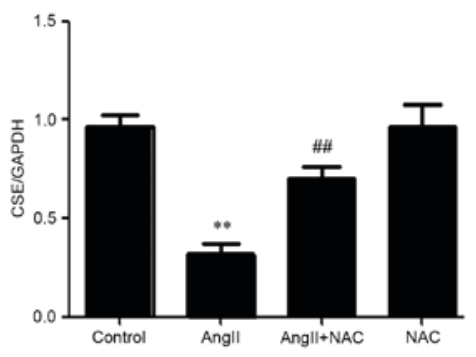

C

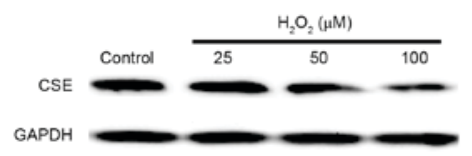

D

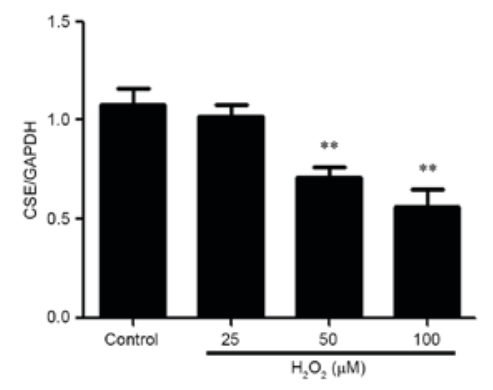

$\mathbf{E}$

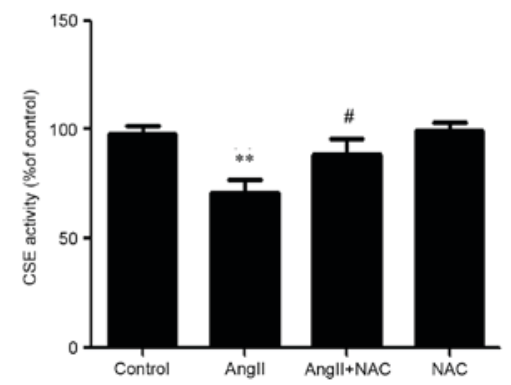

F

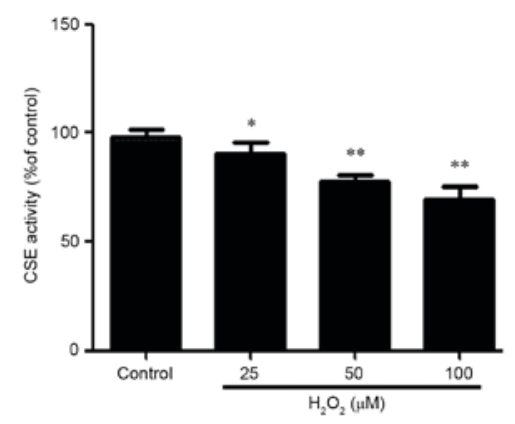

Figure 2. Stimulation of reactive oxygen species production suppressed the expression and activity of CSE in AngII-treated human umbilical vein endothelial cells. (A, B and E) Cells were treated with $10^{-6} \mathrm{M}$ AngII for $24 \mathrm{~h}$, or were pretreated with $1 \mathrm{mM}$ NAC for $1 \mathrm{~h}$ prior to AngII treatment for $24 \mathrm{~h}$. (A and B) Protein expression levels of CSE were determined by western blotting, and (E) the activity levels of CSE were determined by methylene blue spectrophotometric assay. (C, D and F) Cells were treated with the indicated concentrations of $\mathrm{H}_{2} \mathrm{O}_{2}$ for $24 \mathrm{~h}$. (C and D) Protein levels of CSE were determined by western blotting, and (F) the activity levels of CSE were determined by methylene blue spectrophotometric assay. (B and D) Blots in A and C were determined by densitometric analysis. Data are presented as the means \pm standard error of the mean $(n=3) .{ }^{* *} \mathrm{P}<0.01,{ }^{*} \mathrm{P}<0.05$ vs. the control group, ${ }^{\# \prime} \mathrm{P}<0.01,{ }^{\#} \mathrm{P}<0.05$ vs. the AngII treatment group. AngII, angiotensin II; NAC, $\mathrm{N}$-acetyl-L-cysteine; CSE, cystathionine-c-lyase; $\mathrm{H}_{2} \mathrm{O}_{2}$, hydrogen peroxide. 
A

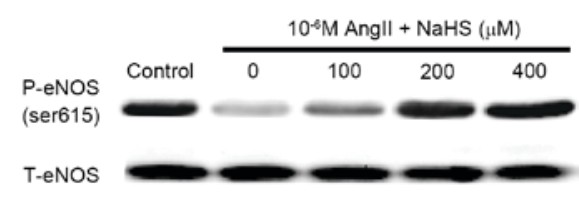

B

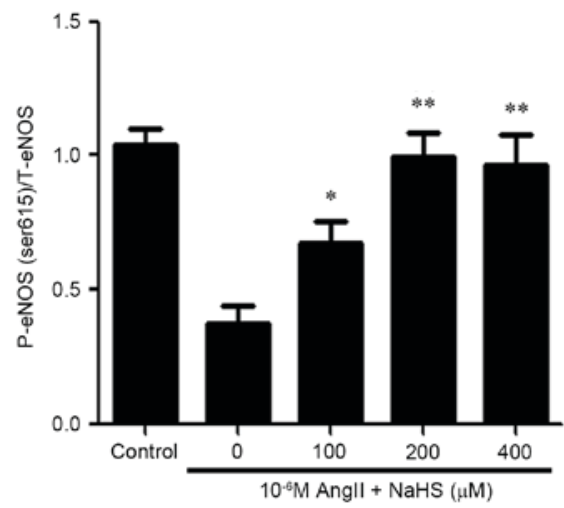

C

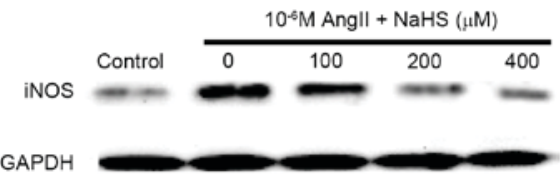

D

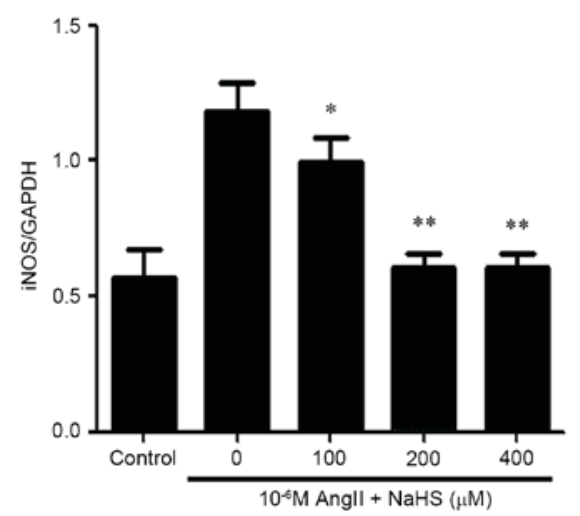

$\mathbf{E}$

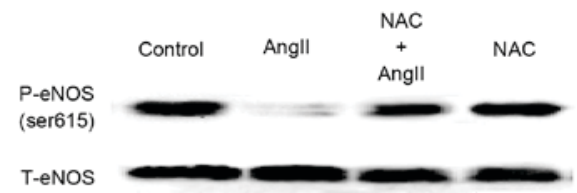

$\mathbf{F}$

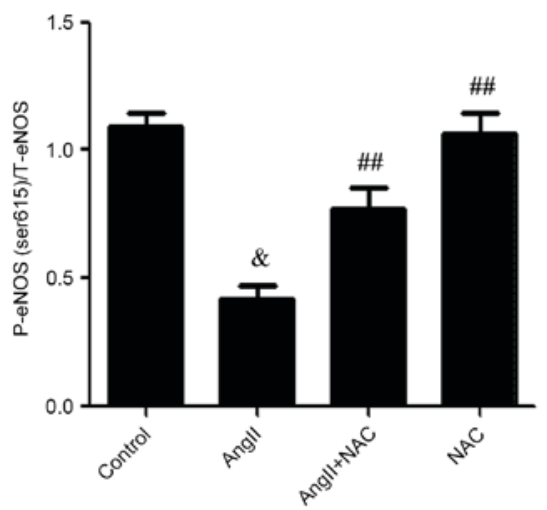

G

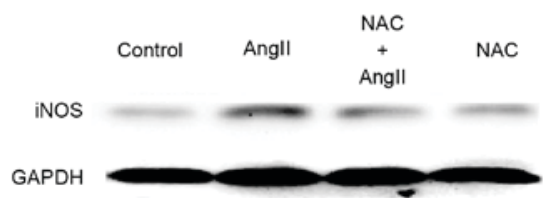

$\mathbf{H}$

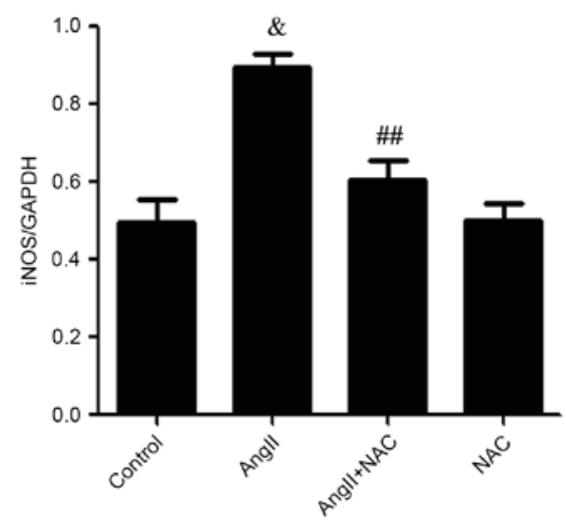

I

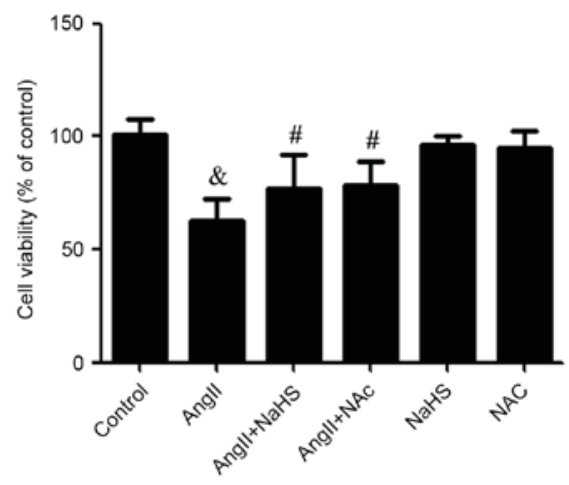

Figure 3. Exogenous $\mathrm{H}_{2} \mathrm{~S}$ ameliorates AngII-induced endothelial dysfunction mediated by reactive oxygen species in human umbilical vein endothelial cells. Cells were pretreated with the indicated concentrations of NaHS for $1 \mathrm{~h}$ and were then treated with $10^{-6} \mathrm{M}$ AngII for $24 \mathrm{~h}$. The protein expression levels of (A and B) p-eNOS (ser615) and (C and D) iNOS were determined by western blotting. (B and D) Blots from $\mathrm{A}$ and $\mathrm{C}$ were semi-quantified by densitometric analysis. Data are presented as the mean \pm standard error of the mean $(\mathrm{n}=3) .{ }^{*} \mathrm{P}<0.05,{ }^{* *} \mathrm{P}<0.01$ vs. the $0 \mu \mathrm{M}$ group. Cells were pretreated with $1 \mathrm{mM} \mathrm{NAC}$ for $1 \mathrm{~h}$ and were then treated with treated with AngII for $24 \mathrm{~h}$. The protein expression levels of (E and F) p-eNOS (ser615) and (G and H) iNOS were determined by western blotting. $(\mathrm{F}$ and $\mathrm{H}$ ) Blots from $\mathrm{E}$ and $\mathrm{G}$ were semi-quantified by densitometric analysis. (I) Cells were incubated with $1 \mathrm{mM}$ NAC or $200 \mu \mathrm{M}$ NaHS only for $24 \mathrm{~h}$, or were pre-incubated with $1 \mathrm{mM}$ NAC or $200 \mu \mathrm{M}$ NaHS for $1 \mathrm{~h}$ before being incubated with $10^{-6} \mathrm{M}$ AngII for $24 \mathrm{~h}$. Cell viability was measured using the Cell Counting kit- 8 assay. Data are presented as the mean \pm standard error of the mean $(n=3) .{ }^{\# \#} \mathrm{P}<0.01$, ${ }^{\text {"P }}<<0.05$ vs. the AngII treatment group,${ }^{\&} \mathrm{P}<0.01$ vs. the control group. AngII, angiotensin II; NaHS, sodium hydrosulfide; NAC, N-acetyl-L-cysteine; p-eNOS, phosphorylated-endothelial nitric oxide synthase; T, total; iNOS, inducible nitric oxide synthase.

injury (33). Since AngII can induce ROS production, the present study aimed to determine the mechanism underlying ROS production in AngII-treated HUVECs. As presented in Fig. 2, HUVECs pretreated with NAC before AngII exhibited increased CSE expression and activity compared with cells treated with AngII. In addition, a well-known exogenous ROS, hydrogen peroxide $\left(\mathrm{H}_{2} \mathrm{O}_{2}\right)$, was used to determine whether ROS induced the downregulation of CSE expression and activity. $\mathrm{H}_{2} \mathrm{O}_{2}$-treated HUVECs exhibited almost undetectable CSE expression and activity compared with untreated control cells. These data indicate that AngII-induced ROS may contribute to the downregulatory effects of AngII on the expression and activity of CSE in HUVECs.

Exogenous $\mathrm{H}_{2} \mathrm{~S}$ ameliorates AngII-induced ED mediated by ROS in HUVECs. The present study demonstrated that 
A

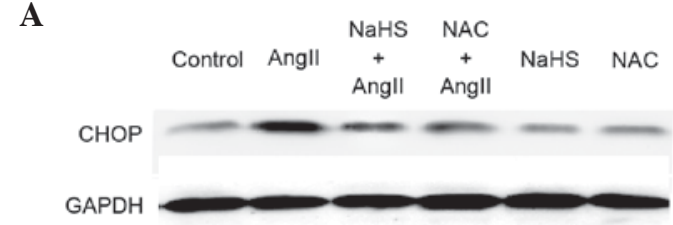

B

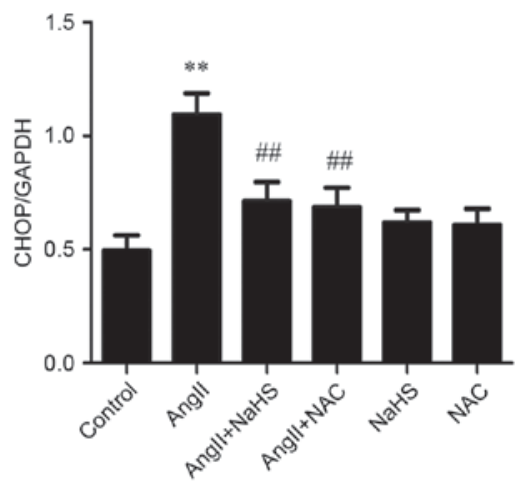

C

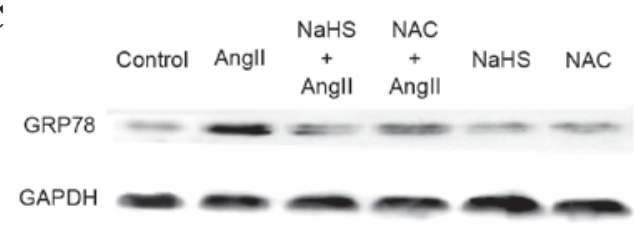

D

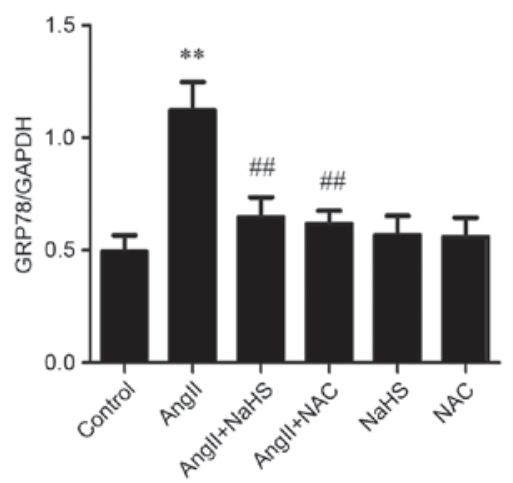

Figure 4. Hydrogen sulfide supplementation or NAC ameliorates AngII-induced GRP78 and CHOP overexpression in human umbilical vein endothelial cells. Cells were incubated with $10^{-6} \mathrm{M}$ AngII, $200 \mu \mathrm{M}$ NaHS or $1 \mathrm{mM}$ NAC for $24 \mathrm{~h}$, or were pretreated with $200 \mu \mathrm{M}$ NaHS or $1 \mathrm{mM} \mathrm{NAC}$ for $1 \mathrm{~h}$ before being treated with $10^{-6} \mathrm{M}$ AngII for $24 \mathrm{~h}$. The protein expression levels of (A and B) CHOP and (C and D) GRP78 were determined by western blot analysis. (B and D) Blots from A and C were semi-quantified by densitometric analysis. Data are presented as the mean \pm standard error of the mean $(n=3) .{ }^{* *} \mathrm{P}<0.01$ vs. the control group, ${ }^{\# \#} \mathrm{P}<0.01$ vs. the AngII treatment group. AngII, angiotensin II; NaHS, sodium hydrosulfide; NAC, N-acetyl-L-cysteine; CHOP, C/EBP-homologous protein; GRP78, glucose-regulated protein 78 .

AngII can inhibit activation of the $\mathrm{CSE} / \mathrm{H}_{2} \mathrm{~S}$ pathway in AngII-treated HUVECs; therefore, the present study used a well-known endothelial protective agent, NaHS, to determine whether NaHS could reduce AngII-induced ED. As presented in Fig. 3, cells treated with NaHS and AngII had lower levels of iNOS, compared with NaHS-unstimulated AngII-treated cells. Conversely, NaHS markedly ameliorated AngII-reduced p-eNOS (ser615) expression. The results suggest that treatment with 200 or $400 \mu \mathrm{M}$ NaHS may inhibit AngII-induced ED. Similarly, treatment with NAC significantly ameliorated
A

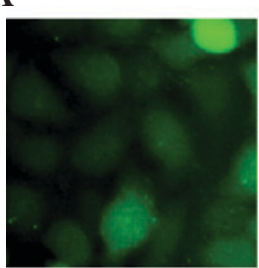

D

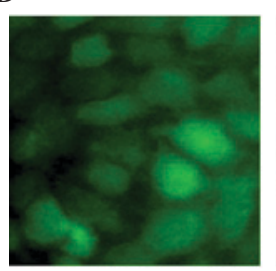

B

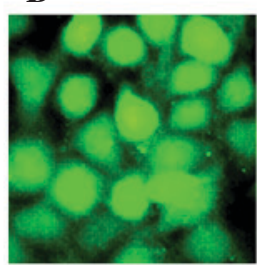

$\mathbf{E}$

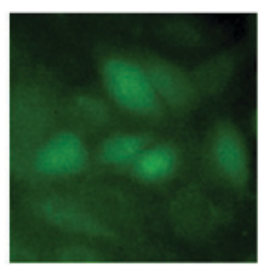

F

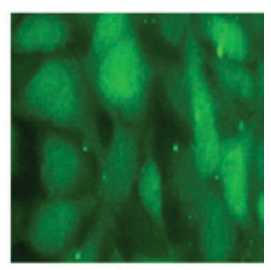

G

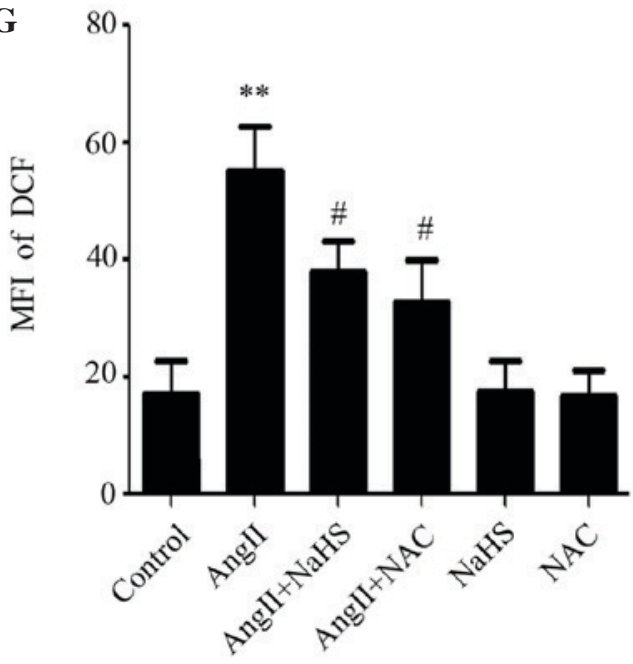

Figure 5. Hydrogen sulfide supplementation or NAC ameliorates AngII-induced reactive oxygen species generation in human umbilical vein endothelial cells. Cells were incubated with $10^{-6} \mathrm{M}$ AngII, $200 \mu \mathrm{M}$ NaHS or $1 \mathrm{mM} \mathrm{NAC}$ for $24 \mathrm{~h}$, or were pretreated with $200 \mu \mathrm{M}$ NaHS or $1 \mathrm{mM}$ NAC for $1 \mathrm{~h}$ before being treated with $10^{-6} \mathrm{M}$ AngII for $24 \mathrm{~h}$. Cellular ROS accumulation was observed by microscopy following 2',7-dichlorodihydrofluorescein diacetate staining. (A) Control; (B) AngII; (C) NaHS + AngII; (D) NAC + AngII; (E) NaHS and (F) NAC groups. Magnification, x400. (G) MFI was determined using ImageJ 1.41 o software with quantitative analysis. Data are presented as the mean \pm standard error of the mean $(n=5)$. ${ }^{* *} \mathrm{P}<0.01$ vs. the control group, ${ }^{\#} \mathrm{P}<0.05$ vs. the AngII treatment group. AngII, angiotensin II; NaHS, sodium hydrosulfide; NAC, N-acetyl-L-cysteine; MFI, mean fluorescent intensity; DCF, dichlorofluorescein.

the expression levels of AngII-suppressed p-eNOS (ser615) (Fig. 3E and F) and AngII-enhanced iNOS (Fig. 3G and H). Notably, cells treated with either NaHS or NAC alongside AngII exhibited improved cell viability compared with AngII-treated cells, whereas treatment with either NaHS or NAC alone did not alter cell viability in HUVECs (Fig. 3I). These data indicate that antioxidants may mediate the effects of $\mathrm{H}_{2} \mathrm{~S}$ on AngII-induced ED.

$\mathrm{H}_{2} \mathrm{~S}$ supplementation or NAC ameliorates AngII-stimulated GRP78 and CHOP overexpression in HUVECs. The present study detected the potential mechanism underlying the protective effects of $\mathrm{H}_{2} \mathrm{~S}$ against AngII-induced ED in HUVECs. It has previously been demonstrated that ROS may induce ER stress. The present results indicated that treatment with the antioxidants NaHS or NAC could suppress AngII-induced 
A

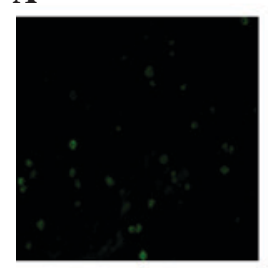

D

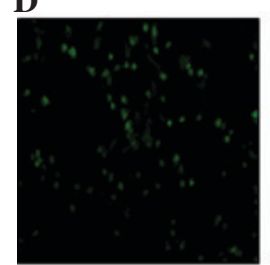

B

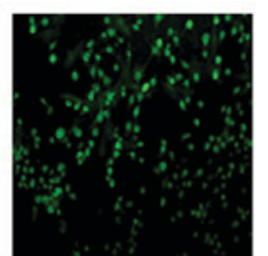

$\mathbf{E}$

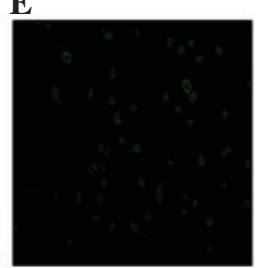

C

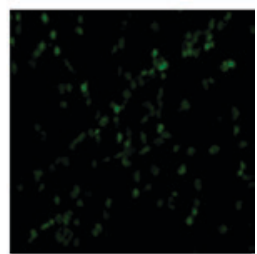

F

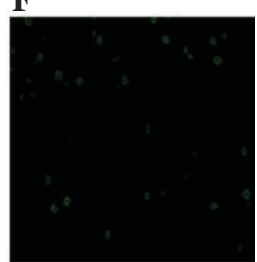

G

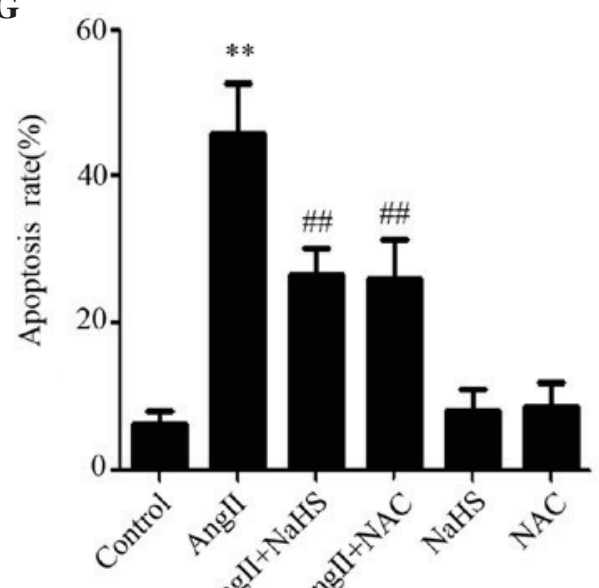

$\mathbf{H}$

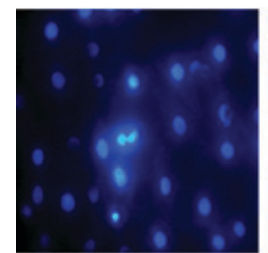

I
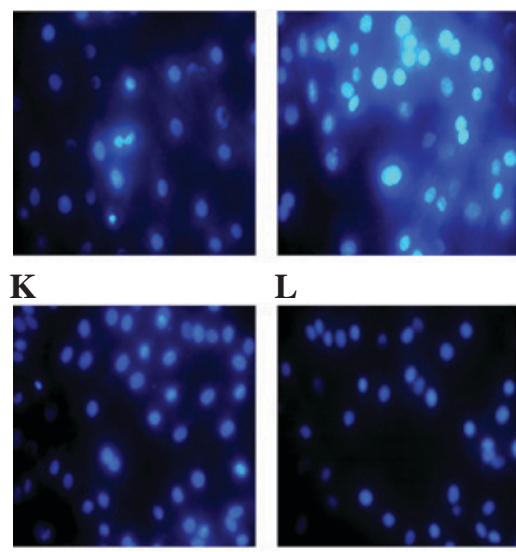

$\mathbf{L}$

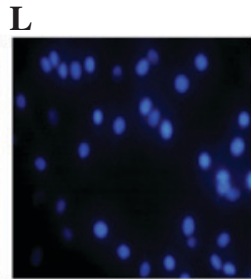

$\mathbf{J}$

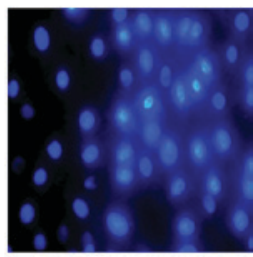

M

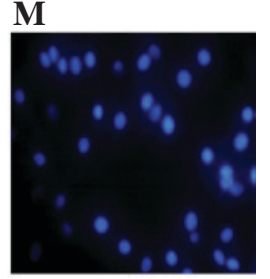

$\mathbf{N}$

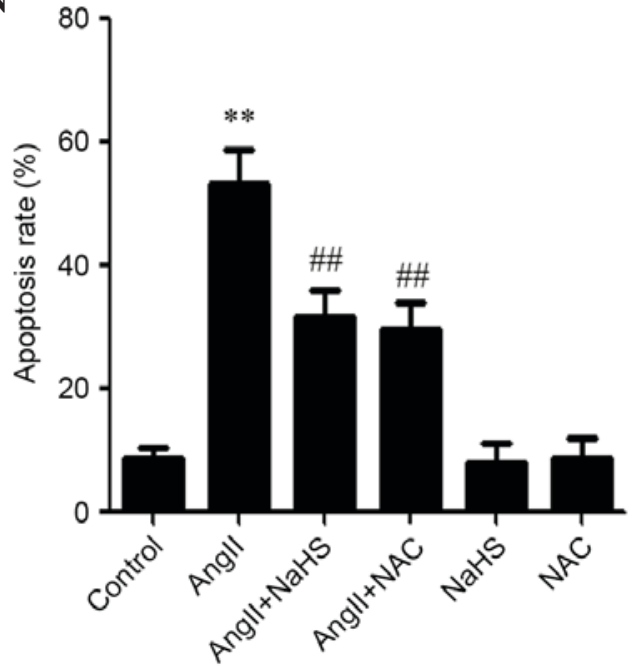

$\mathbf{O}$

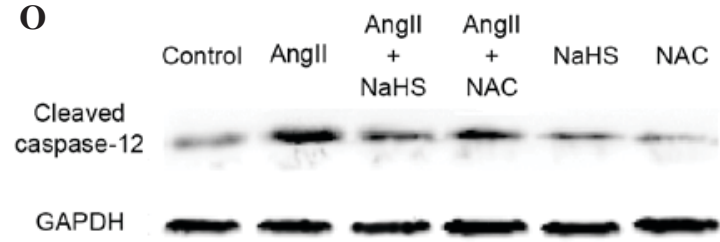

$\mathbf{P}$

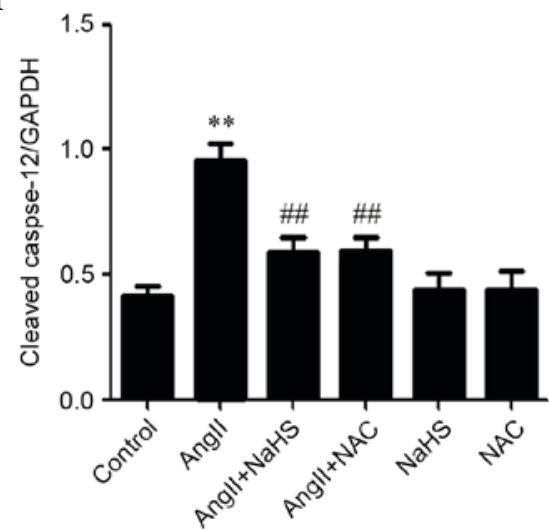

Figure 6. Exogenous hydrogen sulfide and NAC reduce AngII-induced apoptosis in HUVECs. Cells were incubated with $10^{-6} \mathrm{M}$ AngII, $200 \mu \mathrm{M}$ NaHS or $1 \mathrm{mM} \mathrm{NAC}$ for $24 \mathrm{~h}$, or were pretreated with $200 \mu \mathrm{M}$ NaHS or $1 \mathrm{mM}$ NAC for $1 \mathrm{~h}$ before being treated with $10^{-6} \mathrm{M}$ AngII for $24 \mathrm{~h}$. (A-F) HUVECs apoptosis was observed under a microscope after Hochest 33258 staining. Magnification, x200. (G) Mean fluorescent intensity was detected using Image J 1.41o software with quantitative analysis. (H-M) HUVECs apoptosis was observed under a microscope after terminal deoxynucleotidyl transferase dUTP-biotin nick end labeling staining. Magnification, x100 (A and $\mathrm{H}$ ) Control (untreated HUVECs); (B and I) AngII; (C and J) NaHS + AngII; (D and K) NAC + AngII; (E and L) NaHS and (F and M) NAC groups. (N) Mean fluorescent intensity was detected using Image J 1.41o software with quantitative analysis. ( $\mathrm{O}$ and $\mathrm{P}$ ) The protein levels of caspase-12 were determined by western blot analysis. (P) Blot presented in $\mathrm{O}$ was semi-quantified by densitometric analysis. Data are presented as the mean \pm standard error of the mean $(n=5) .{ }^{* *} \mathrm{P}<0.01 \mathrm{vs}$. the control group, ${ }^{\# \#} \mathrm{P}<0.05$ vs. the AngII treatment group. AngII, angiotensin II; NaHS, sodium hydrosulfide; NAC, N-acetyl-L-cysteine; HUVECs, human umbilical vein endothelial cells.

GRP78 and CHOP expression, whereas either NaHS or NAC alone did not alter the expression levels of GRP78 and CHOP in HUVECs (Fig. 4). These data suggest that the inhibitory effects of $\mathrm{H}_{2} \mathrm{~S}$ may protect against AngII-induced dysfunction in HUVECs via suppressing ER stress.

$\mathrm{H}_{2} \mathrm{~S}$ supplementation or NAC ameliorates AngII-induced ROS generation in HUVECs. To determine whether the cytoprotective effects of $\mathrm{H}_{2} \mathrm{~S}$ against AngII-induced ED were due to its antioxidative activity, NaHS and NAC were used to treat HUVECs. AngII exposure markedly enhanced intracellular ROS generation in HUVECs (Fig. 5B). However, pretreatment with either NaHS or NAC for 60 min markedly attenuated AngII-induced ROS accumulation in HUVECs (Fig. 5C and D). Pretreatment with NAC had a similar antioxidant effect to NaHS against AngII-induced ROS accumulation, whereas NaHS or NAC treatment alone did not alter base intracellular ROS levels (Fig. 5E and F).

Exogenous $\mathrm{H}_{2} \mathrm{~S}$ and NAC reduce AngII-induced apoptosis in HUVECs. The present study also determined the effects 
of NaHS and NAC on AngII-induced apoptosis. As shown in Fig. 6, AngII-stimulated HUVECs exhibited typical characteristics of apoptosis, including chromatin condensation, nuclear shrinkage, and the presence of apoptotic bodies. However, treatment with either NaHS or NAC, alongside AngII, resulted in amelioration of the typical characteristics of apoptosis, including chromatin condensation, nuclear shrinkage, and the presence of apoptotic bodies compared with in cells treated with AngII only. Treatment with NaHS or NAC alone did not markedly alter cell morphology or the percentage of apoptotic HUVECs. Consistent with these results, the protein expression levels of cleaved caspase-12 were examined by western blot analysis, and were reduced in AngII-treated cells following NaHS or NAC treatment. However, treatment with either NaHS or NAC alone did not alter the expression of cleaved caspase-12. These findings indicate that exogenous $\mathrm{H}_{2} \mathrm{~S}$ protects HUVECs against AngII-induced ER stress.

\section{Discussion}

RAS activity and oxidative stress are two major interacting pathogenic factors associated with $\mathrm{ED}$, which is the initiating factor and pathological basis of CVD $(34,35)$. As an important mediator of endothelial function maintenance, reduced levels of nitric oxide (NO) could accelerate the ED process (36). Cellular and animal studies have demonstrated that $\mathrm{NO}$, via constitutive NOS isoforms, modulates endothelial cell dilation and blood flow distribution, and low levels of p-eNOS activity are associated with injured endothelial function (37,38). However, high levels of iNOS also exert a similar effect (39). Nakao et al (40) demonstrated that suppressed p-eNOS and enhanced iNOS expression are associated with AngII cytotoxicity; together with the present findings, these results suggested that AngII may result in HUVECs dysfunction.

Emerging evidence from experimental and clinical research has indicated that ER stress is involved in CVD with ED (41) and RAS activity (42). ER stress modulates various factors, including GRP78 and CHOP. Oxidative stress (43) or AngII stimulation (44) have been suggested to trigger GRP78 and $\mathrm{CHOP}$ overexpression. Furthermore, AngII can upregulate the expression of inflammatory mediators, including GRP78 and CHOP, leading to cytotoxicity in HUVECs. The present findings are in agreement with those of a previous study, which demonstrated that high levels of AngII led to cardiac damage and vascular ED via ER stress (23). CSE serves atherogenic and endothelial cytoprotective roles in CVD $(27,45)$. Conversely, AngII exerts cytotoxic effects, and in the present study AngII was shown to downregulate the expression and activity of CSE in HUVECs, which was accompanied by decreased cell viability. In addition, insufficient production of endogenous $\mathrm{H}_{2} \mathrm{~S}$ or inhibition of its synthesis have been reported to enhance the overproduction of ROS in HUVECs (46). Taken together, it may be hypothesized that AngII-induced ER stress leads to ED in HUVECs via the inhibition of endogenous $\mathrm{H}_{2} \mathrm{~S}$ production.

Insufficient production of endogenous $\mathrm{H}_{2} \mathrm{~S}$ has been reported to be associated with AngII-induced cytotoxicity via oxidative stress (47). The present study, alongside a previous study, confirmed that ROS, such as $\mathrm{H}_{2} \mathrm{O}_{2}$, serve a primary role in ER stress, are regulated by AngII and are responsible for the consequent generation of ED (48). Furthermore, the present study demonstrated that treatment with the exogenous ROS, $\mathrm{H}_{2} \mathrm{O}_{2}$, downregulated the expression and activity of CSE; the inhibitory effects of $\mathrm{H}_{2} \mathrm{O}_{2}$ were similar to those of AngII in HUVECs. Subsequently, HUVECs were treated with NAC prior to AngII exposure; the results demonstrated that NAC suppressed overproduction of ROS and insufficient productions of endogenous $\mathrm{H}_{2} \mathrm{~S}$. These findings suggested that ROS serves a key role in the inhibition of CSE induced by AngII in HUVECs.

The present study also demonstrated that the effects of exogenous $\mathrm{H}_{2} \mathrm{~S}$ on AngII-induced ED were due to antioxidative mechanisms. The findings indicated that $\mathrm{H}_{2} \mathrm{~S}$ supplementation prior to AngII treatment in HUVECs resulted in a reduction in the expression levels of iNOS, an increase in p-eNOS (Ser615) expression and increased cell viability. Furthermore, treatment with NAC before AngII exposure not only exerted inhibitory effects on iNOS expression, but also enhanced p-eNOS (Ser615) expression and cell viability, whereas supplementation of $\mathrm{H}_{2} \mathrm{~S}(\mathrm{NaHS})$ prior to AngII-treated HUVECs had similar effects. The present study further explored the potential mechanism underlying the protective effects of exogenous $\mathrm{H}_{2} \mathrm{~S}$, by treating cells with either NaHS or NAC prior to AngII exposure. Since NaHS or NAC exert similar antioxidative effects, NAC, similar to NaHS, was able to reduce ER stress, including GRP78 and CHOP expression. In addition, DCFH-DA was used to detect cellular ROS accumulation. The results indicated that the antioxidative effects of $\mathrm{H}_{2} \mathrm{~S}$ may exert protection against AngII-induce ED by suppressing ER stress. ROS are associated with accelerated ER malfunction (49); the present study demonstrated that in HUVECs pretreated with NaHS or NAC prior to AngII exposure, ROS overproduction was inhibited.

ER stress is particularly associated with apoptosis. Song et al (50) demonstrated that GRP78 and CHOP are markedly activated in apoptosis. The present study pretreated HUVECs with NaHS or NAC, prior to AngII exposure, and TUNEL and Hoechst 33258 staining were used to detect apoptosis. The results indicated that pretreatment with either NaHS or NAC significantly decreased AngII-induced apoptosis and cleaved caspase- 12 expression. In addition, Qabazard et al (51) reported that $\mathrm{H}_{2} \mathrm{~S}$ significantly suppressed $\mathrm{H}_{2} \mathrm{O}_{2}$-induced ER stress in bovine aortic endothelial cells, and ameliorated cell apoptosis.

In conclusion, using AngII-treated HUVECs, the present study demonstrated that ROS participates in AngII-induced ER stress-mediated ED, by inhibiting the expression and activity of CSE. In addition, $\mathrm{H}_{2} \mathrm{~S}$ supplementation may be considered a beneficial antioxidative therapy in AngII-induced ED via the suppression of ER stress. The results of the present study provide novel evidence to suggest that exogenous $\mathrm{H}_{2} \mathrm{~S}$ may be considered a novel therapeutic strategy for the treatment of CVD.

\section{Acknowledgements}

The present study was supported by the National Natural Science Foundation of China (grant no. 81100106), Aid Programme for Science and Technology Innovative Research Team. 


\section{References}

1. Ding Z, Liu S, Wang X, Dai Y, Khaidakov M, Romeo F and Mehta JL: LOX-1, oxidant stress, mtDNA damage, autophagy, and immune response in atherosclerosis. Can J Physiol Pharmacol 92: 524-530, 2014

2. Messner B and Bernhard D: Smoking and cardiovascular disease: Mechanisms of endothelial dysfunction and early atherogenesis. Arterioscler Thromb Vasc Biol 34: 509-515, 2014.

3. Stam F, van Guldener C, Becker A, Dekker JM, Heine RJ, Bouter LM and Stehouwer CD: Endothelial dysfunction contributes to renal function-associated cardiovascular mortality in a population with mild renal insufficiency: The Hoorn study. J Am Soc Nephrol 17: 537-545, 2006.

4. Geronikaki AA, Pitta EP and Liaras KS: Thiazoles and thiazolidinones as antioxidants. Curr Med Chem 20: 4460-4480, 2013.

5. Wang X, Yuan B, Dong W, Yang B, Yang Y, Lin X and Gong G: Humid heat exposure induced oxidative stress and apoptosis in cardiomyocytes through the angiotensin II signaling pathway. Heart Vessels 30: 396-405, 2015

6. Li L, Li N, Pang W, Zhang X, Hammock BD, Ai D and Zhu Y: Opposite effects of gene deficiency and pharmacological inhibition of soluble epoxide hydrolase on cardiac fibrosis. PLoS One 9: e94092, 2014

7. Johar S, Cave AC, Narayanapanicker A, Grieve DJ and Shah AM: Aldosterone mediates angiotensin II-induced interstitial cardiac fibrosis via a Nox2-containing NADPH oxidase. FASEB J 20: 1546-1548, 2006.

8. Kittikulsuth W, Looney SW and Pollock DM: Endothelin $\mathrm{ET}(\mathrm{B})$ receptors contribute to sex differences in blood pressure elevation in angiotensin II hypertensive rats on a high-salt diet. Clin Exp Pharmacol Physiol 40: 362-370, 2013.

9. Marrachelli VG, Mastronardi ML, Sarr M, Soleti R, Leonetti D, Martínez MC and Andriantsitohaina R: Sonic hedgehog carried by microparticles corrects angiotensin II-induced hypertension and endothelial dysfunction in mice. PLoS One 8: e72861, 2013.

10. Schäfer SC, Pellegrin M, Wyss C, Aubert JF, Nussberger J, Hayoz D, Lehr HA and Mazzolai L: Intravital microscopy reveals endothelial dysfunction in resistance arterioles in Angiotensin II-induced hypertension. Hypertens Res 35: 855-861, 2012

11. Lin LY, Lin CY, Su TC and Liau CS: Angiotensin II-induced apoptosis in human endothelial cells is inhibited by adiponectin through restoration of the association between endothelial nitric oxide synthase and heat shock protein 90 . FEBS Lett 574 106-110, 2004.

12. Matsumoto S, Shimabukuro M, Fukuda D, Soeki T, Yamakawa K, Masuzaki H and Sata M: Azilsartan, an angiotensin II type 1 receptor blocker, restores endothelial function by reducing vascular inflammation and by increasing the phosphorylation ratio Ser (1177)/Thr(497) of endothelial nitric oxide synthase in diabetic mice. Cardiovasc Diabetol 13: 30, 2014

13. Billings FT IV, Pretorius M, Schildcrout JS, Mercaldo ND, Byrne JG, Ikizler TA and Brown NJ: Obesity and oxidative stress predict AKI after cardiac surgery. J Am Soc Nephrol 23: 1221-1228, 2012

14. Matsumoto T, Kobayashi $\mathrm{T}$ and Kamata K: Relationships among ET-1, PPARgamma, oxidative stress and endothelial dysfunction in diabetic animals. J Smooth Muscle Res 44: 41-55, 2008.

15. Xing S, Yang X, Li W, Bian F, Wu D, Chi J, Xu G, Zhang Y and Jin S: Salidroside stimulates mitochondrial biogenesis and protects against $\mathrm{H}_{2} \mathrm{O}_{2}$-induced endothelial dysfunction. Oxid Med Cell Longev 2014: 904834, 2014.

16. Kei A, Tellis C, Liberopoulos E, Tselepis A and Elisaf M Effect of switch to the highest dose of rosuvastatin versus add-on-statin fenofibrate versus add-on-statin nicotinic acid/laropiprant on oxidative stress markers in patients with mixed dyslipidemia. Cardiovasc Ther 32: 139-146, 2014.

17. Bozaykut P, Sozen E, Yazgan B, Karademir B and Kartal-Ozer N: The role of hypercholesterolemic diet and vitamin E on Nrf2 pathway, endoplasmic reticulum stress and proteasome activity. Free Radic Biol Med 75 (Suppl 1): S24, 2014.

18. Hasnain SZ, Prins JB and McGuckin MA: Oxidative and endoplasmic reticulum stress in $\beta$-cell dysfunction in diabetes. J Mol Endocrinol 56: R33-R54, 2016.
19. Cimellaro A, Perticone M, Fiorentino TV, Sciacqua A and Hribal ML: Role of endoplasmic reticulum stress in endothelial dysfunction. Nutr Metab Cardiovasc Dis 26: 863-871, 2016.

20. Simon-Szabó L, Kokas M, Mandl J, Kéri G and Csala M: Metformin attenuates palmitate-induced endoplasmic reticulum stress, serine phosphorylation of IRS-1 and apoptosis in rat insulinoma cells. PLoS One 9: e97868, 2014.

21. Wang XY, Yang CT, Zheng DD, Mo LQ, Lan AP, Yang ZL, Hu F, Chen PX, Liao XX and Feng JQ: Hydrogen sulfide protects H9c2 cells against doxorubicin-induced cardiotoxicity through inhibition of endoplasmic reticulum stress. Mol Cell Biochem 363: 419-426, 2012.

22. Li PC, Yang CC, Hsu SP and Chien CT: Repetitive progressive thermal preconditioning hinders thrombosis by reinforcing phosphatidylinositol 3-kinase/Akt-dependent heat-shock protein/endothelial nitric oxide synthase signaling. J Vasc Surg 56: 159-170, 2012.

23. Kassan M, Galán M, Partyka M, Saifudeen Z, Henrion D, Trebak $\mathrm{M}$ and Matrougui K: Endoplasmic reticulum stress is involved in cardiac damage and vascular endothelial dysfunction in hypertensive mice. Arterioscler Thromb Vasc Biol 32: 1652-1661, 2012

24. Wang X, Bai YP, Hong D, Gao HC, Li LF, Li CC, Zhu LP, Sun Q and Zhang GG: Ang II induces capillary formation from endothelial cells via the AT1R-dependent inositol requiring enzyme 1 pathway. Biochem Biophys Res Commun 434: 552-558, 2013.

25. Chen ZF, Zhao B, Tang XY, Li W, Zhu LL, Tang CS, DU JB and Jin HF: Hydrogen sulfide regulates vascular endoplasmic reticulum stress in apolipoprotein $\mathrm{E}$ knockout mice. Chin Med $\mathrm{J}$ (Engl) 124: 3460-3467, 2011

26. Xue H, Yuan P, Ni J, Li C, Shao D, Liu J, Shen Y, Wang Z, Zhou L, Zhang W, et al: $\mathrm{H}(2) \mathrm{S}$ inhibits hyperglycemia-induced intrarenal renin-angiotensin system activation via attenuation of reactive oxygen species generation. PLoS One 8: e74366, 2013.

27. Wen YD, Wang H, Kho SH, Rinkiko S, Sheng X, Shen HM and Zhu YZ: Hydrogen sulfide protects HUVECs against hydrogen peroxide induced mitochondrial dysfunction and oxidative stress. PLoS One 8: e53147, 2013.

28. Marzetti E, Calvani R, Cesari M, Buford TW, Lorenzi M, Behnke BJ and Leeuwenburgh C: Mitochondrial dysfunction and sarcopenia of aging: From signaling pathways to clinical trials. Int J Biochem Cell Biol 45: 2288-2301, 2013.

29. Tomada I, Negrão R, Almeida H and Neves D: Long-term high-fat consumption leads to downregulation of Akt phosphorylation of eNOS at Ser1177 and upregulation of Sirtuin-1 expression in rat cavernous tissue. Age (Dordr) 36: 597-611, 2014

30. Ripa P, Ornello R, Pistoia F, Carolei A and Sacco S: The renin-angiotensin system: A possible contributor to migraine pathogenesis and prophylaxis. Expert Rev Neurother 14: 1043-1055, 2014

31. Wang W, Qiu L, Howard A, Solis N, Li C, Wang X, Kopp JB and Levi M: Protective effects of aliskiren and valsartan in mice with diabetic nephropathy. J Renin Angiotensin Aldosterone Syst 15: 384-395, 2014.

32. Xu J, Wang G, Wang Y, Liu Q, Xu W, Tan Y and Cai L: Diabetes- and angiotensin II-induced cardiac endoplasmic reticulum stress and cell death: Metallothionein protection. J Cell Mol Med 13: 1499-1512, 2009

33. Park MH, Heo SJ, Park PJ, Moon SH, Sung SH, Jeon BT and Lee SH: 6,6'-bieckol isolated from ecklonia cava protects oxidative stress through inhibiting expression of ROS and proinflammatory enzymes in high-glucose-induced human umbilical vein endothelial cells. Appl Biochem Biotechnol 174: 632-643, 2014

34. Liu JJ, Li DL, Zhou J, Sun L, Zhao M, Kong SS, Wang YH, Yu XJ, Zhou J and Zang WJ: Acetylcholine prevents angiotensin II-induced oxidative stress and apoptosis in H9c2 cells. Apoptosis 16: 94-103, 2011.

35. Wong WT, Tian XY and Huang Y: Endothelial dysfunction in diabetes and hypertension: Cross talk in RAS, BMP4, and ROS-dependent COX-2-derived prostanoids. J Cardiovasc Pharmacol 61: 204-214, 2013

36. Dudzinski DM and Michel T: Life history of eNOS: Partners and pathways. Cardiovasc Res 75: 247-260, 2007.

37. Heltianu C, Costache G, Gafencu A, Diaconu M, Bodeanu M, Cristea C, Azibi K, Poenaru L and Simionescu M: Relationship of eNOS gene variants to diseases that have in common an endothelial cell dysfunction. J Cell Mol Med 9: 135-142, 2005. 
38. El Accaoui RN, Gould ST, Hajj GP, Chu Y, Davis MK, Kraft DC, Lund DD, Brooks RM, Doshi H, Zimmerman KA, et al: Aortic valve sclerosis in mice deficient in endothelial nitric oxide synthase. Am J Physiol Heart Circ Physiol 306: H1302-H1313, 2014.

39. Albrecht EW, Stegeman CA, Heeringa P, Henning RH and van Goor H: Protective role of endothelial nitric oxide synthase. J Pathol 199: 8-17, 2003.

40. Nakao T, Morita H, Maemura K, Amiya E, Inajima T, Saito Y, Watanabe M, Manabe I, Kurabayashi M, Nagai R and Komuro I: Melatonin ameliorates angiotensin II-induced vascular endothelial damage via its antioxidative properties. J Pineal Res 55: 287-293, 2013

41. Zhou B, Li H, Liu J, Xu L, Zang W, Wu S and Sun H: Intermittent injections of osteocalcin reverse autophagic dysfunction and endoplasmic reticulum stress resulting from diet-induced obesity in the vascular tissue via the NFkB-p65-dependent mechanism. Cell Cycle 12: 1901-1913, 2013.

42. Finckenberg P, Eriksson O, Baumann M, Merasto S, Lalowski MM, Levijoki J, Haasio K, Kytö V, Muller DN, Luft FC, et al: Caloric restriction ameliorates angiotensin II-induced mitochondrial remodeling and cardiac hypertrophy. Hypertension 59: 76-84, 2012.

43. Watanabe $Y$, Suzuki O, Haruyama $T$ and Akaike $T$ : Interferon-gamma induces reactive oxygen species and endoplasmic reticulum stress at the hepatic apoptosis. J Cell Biochem 89: 244-253, 2003.

44. Wencker D, Chandra M, Nguyen K, Miao W, Garantziotis S, Factor SM, Shirani J, Armstrong RC and Kitsis RN: A mechanistic role for cardiac myocyte apoptosis in heart failure. J Clin Invest 111: 1497-1504, 2003.
45. Szczesny B, Módis K, Yanagi K, Coletta C, Le Trionnaire S, Perry A, Wood ME, Whiteman M and Szabo C: AP39, a novel mitochondria-targeted hydrogen sulfide donor, stimulates cellular bioenergetics, exerts cytoprotective effects and protects against the loss of mitochondrial DNA integrity in oxidatively stressed endothelial cells in vitro. Nitric Oxide 41: 120-130, 2014.

46. Pan LL, Liu XH, Gong QH, Wu D and Zhu YZ: Hydrogen sulfide attenuated tumor necrosis factor- $\alpha$-induced inflammatory signaling and dysfunction in vascular endothelial cells. PLoS One 6: e19766, 2011.

47. Snijder PM, Frenay AS, de Boer RA, Pasch A, Hillebrands JL, Leuvenink HG and van Goor $\mathrm{H}$ : Exogenous administration of thiosulfate, a donor of hydrogen sulfide, attenuates angiotensin II-induced hypertensive heart disease in rats. Br J Pharmacol 172: 1494-1504, 2015.

48. Zhang Y, Tang ZH, Ren Z, Qu SL, Liu MH, Liu LS and Jiang ZS Hydrogen sulfide, the next potent preventive and therapeutic agent in aging and age-associated diseases. Mol Cell Biol 33: 1104-1113, 2013.

49. Chaudhari N, Talwar P, Parimisetty A, Lefebvre d'Hellencourt C and Ravanan P: A molecular web: Endoplasmic reticulum stress, inflammation, and oxidative stress. Front Cell Neurosci 8: 213, 2014.

50. Song XJ, Yang CY, Liu B, Wei Q, Korkor MT, Liu JY and Yang P: Atorvastatin inhibits myocardial cell apoptosis in a rat model with post-myocardial infarction heart failure by downregulating ER stress response. Int J Med Sci 8: 564-572, 2011.

51. Qabazard B, Ahmed S, Li L, Arlt VM, Moore PK and Stürzenbaum SR: C. elegans aging is modulated by hydrogen sulfide and the sulfhydrylase/cysteine synthase cysl-2. PLoS One 8: e80135, 2013. 